\title{
In vitro and in vivo evidence on the site of neutralization of equine chorionic gonadotrophin (eCG) by an eCG antiserum
}

\author{
X. Wang ${ }^{1}$, A. R. Kole ${ }^{2}$ and G. S. Greenwald ${ }^{3 *}$ \\ ${ }^{1}$ Ligand Pharmaceuticals, La Jolla, CA 92037, USA; ${ }^{2}$ Ananda Mohan College, Calcutta, India; and \\ ${ }^{3}$ Department of Physiology, Ralph L. Smith Research Center, University of Kansas Medical Center, \\ Kansas City, KS 66160-7401, USA
}

\begin{abstract}
This study was designed to determine whether the major site of eCG neutralization by an antiserum to the hormone is at the peripheral or ovarian level. Hamsters hypophysectomized at oestrus were injected s.c. with 25 iu eCG. Three days later, preovulatory follicles were dissected and cultured for $5 \mathrm{~h}$ and the medium was changed every hour. At the end of the first hour of incubation, oestradiol and androstenedione accumulation was high, with a sharp drop over the next $4 \mathrm{~h}$, whereas progesterone concentrations did not change over the entire period. Addition of eCG antiserum to the incubated follicles did not affect steroidogenesis. Addition of 1.0 iu eCG in the second hour or every hour sustained oestradiol production at supraphysiological amounts. However, addition of eCG plus eCG antiserum every hour eliminated the stimulatory effects of eCG on oestradiol production. In another experiment, hamsters injected with eCG were treated 3 days later by i.p. injection of eCG antiserum and groups of animals were killed over the next $8 \mathrm{~h}$. Serum samples before and after injecting eCG antiserum were incubated overnight with a goat anti-rabbit immunoglobulin to separate free, unbound eCG from bound eCG. At time zero (before injecting the antiserum) free eCG was increased, but within $\mathrm{I} \mathrm{h}$ after eCG antiserum there was an eightfold decrease of the hormone, and these concentrations were maintained over the next $7 \mathrm{~h}$. The fall in unbound eCG in vivo coincided with the decay in serum oestradiol and androstenedione. These results obtained in vitro and in vivo demonstrate that the long biological half-life of eCG is essential to replenish the supply provided to the ovary constantly to maintain steroidogenesis; $\mathrm{eCG}$ antiserum inactivates eCG in serum but not by complexing with eCG at the receptor of the follicular cell surface.
\end{abstract}

\section{Introduction}

Cole and Hart (1930) and Zondek (1930) were the first to isolate equine chorionic gonadotrophin $(\mathrm{eCG})$. In the former study, the endpoint was injecting eCG into immature rats and mice, and the consequent increase in ovarian mass was used to map changing hormonal concentrations during pregnancy. Ovarian histology revealed the presence of numerous antral follicles, some of which were undergoing luteinization (Cole and Hart, 1930). Thus, in the earliest investigations, the efficacy of eCG in stimulating ovarian development in rodents was established and since then it has been routinely used for that purpose (for early references, see Cole, 1975).

One of the advantages of using eCG is its long half-life. When injected i.v. into adult rats, its half-life is $26 \mathrm{~h}$ compared with $4.9 \mathrm{~h}$ for hCG and $15 \mathrm{~min}$ for ovine LH (Parlow and Ward, 1961). Intravenous injection of a radioiodinated preparation of highly purified eCG revealed that about half of the hormone disappeared by $60 \mathrm{~min}$ and that the half-life of the second component was 6-7 h (Aggarwal and Papkoff, 1981).

*Reprint requests.

Received 30 December 1994.
The long half-life of eCG presumably results from its greater carbohydrate content $(41 \%)$ compared with other glycoprotein hormones (Papkoff et al., 1978). The hormone is also unique in that, in rodents, it has considerable FSH- as well as LH-like properties; using the Steelman-Pohley assay for FSH, eCG has 75.9 times the potency of NIH-FSH-S10 (Papkoff et al., 1978). However, immunologically, eCG is closely related to equine $\mathrm{LH}$, while the inhibition curve to equine FSH is non-parallel and the binding of eCG to the equine FSH receptor is much less (Farmer and Papkoff, 1979; for recent references see Murphy and Martinuk, 1991).

A model extensively used to establish the sequence of morphological and biochemical changes after induced follicular atresia consists of injecting hypophysectomized hamsters with $\mathrm{eCG}$, and then, 3 days later, injecting a polyclonal antibody to eCG; this procedure results in a marked fall in serum oestrogens and androgens within $1 \mathrm{~h}$, and pyknotic granulosa cells morphological evidence of atresia - appear within $4 \mathrm{~h}$ (for references, see Greenwald, 1989).

One of the unanswered questions raised by this model is addressed in the present study: does eCG antiserum neutralize eCG by combining with it in blood or by complexing with 
eCG bound to ovarian receptors? In general, polyclonal antibodies bind not only to free ligand in circulation but also to specific cell surface proteins and cross-link them into large clusters (Alberts et al., 1989). The experiments presented here were designed to resolve this question by explanting antral follicles previously exposed for 3 days in vivo to eCG and then subjected to incubation with or without eCG-antiserum, and by injecting eCG and eCG antiserum into hypophysectomized hamsters and then measuring free and bound serum concentrations of $\mathrm{eCG}$.

\section{Materials and Methods}

\section{Animals}

Sexually mature golden hamsters, weighing 90-100 g, were purchased from Sasco Laboratories (Omaha, NE). The animals were maintained under a photoperiod of $14 \mathrm{~h}$ light: $10 \mathrm{~h}$ dark (lights on at 05:00 h). After monitoring three consecutive 4 day cycles by the vaginal discharge present on the morning of oestrus (day 1) the animals were hypophysectomized by the parapharyngeal approach under i.p. pentobarbital $\left(8 \mathrm{mg} \mathrm{kg}^{-1}\right.$ body mass; Veterinary Laboratories, Olathe, KS) between 09:00 and 11:00 h on day 1 and injected immediately s.c. with 25 iu eCG (Sigma, St Louis, MO).

\section{Follicular steroidogenesis in vitro}

On the morning of day 4, hypophysectomized-eCG injected hamsters were decapitated and large antral follicles were dissected from the ovaries with watchmaker forceps and incubated in groups of five (time 0 ). There were four replicates per group. The follicles were incubated at room temperature in $1 \mathrm{ml}$ medium 199 (Gibco, Grand Island, NY). At the end of every hour, medium was collected and $1 \mathrm{ml}$ fresh medium was added. The collected medium was used for radioimmunoassay of oestradiol, androstenedione and progesterone.

After preincubation for $1 \mathrm{~h}(\mathrm{~h} 1), 3,10$, or $100 \mu \mathrm{ll}$ of eCG antiserum (which was raised in rabbits) or an equal volume of normal rabbit serum (NRS), as a control, were added every hour for the next $4 \mathrm{~h}$. In separate experiments, follicles (from eCG-treated animals) were also preincubated for $I \mathrm{~h}$, and the medium was withdrawn and $1.0 \mathrm{iu}$ eCG added only at the second hour or every hour for the next $4 \mathrm{~h}$.

\section{Histology of isolated follicles}

After incubation, isolated follicles from control groups and groups treated with eCG-antiserum were fixed in Bouin's fluid for $2 \mathrm{~h}$ and placed in agar blocks for histological processing. Serial sections were then cut at $7 \mu \mathrm{m}$ and stained with haematoxylin and eosin. The presence of five pyknotic nuclei in the largest cross-section of the follicle in which the nucleolus of the oocyte was present was considered as a sign of early atresia.

\section{Radioimmunoassay for unbound eCG}

On the basis of results of the previous experiments performed in vitro, the next step was to measure the concentrations of circulating free (i.e., unbound) serum eCG before and after administering eCG-antiserum to hamsters hypophysectomized and injected with eCG on day 1 . of the oestrous cycle. Serum was collected at time 0 and 1, 2, 4 and $8 \mathrm{~h}$ after eCG antiserum. There were four animals in each group. Each sample $(150 \mu \mathrm{l}$ serum) was incubated at $4^{\circ} \mathrm{C}$ for $24 \mathrm{~h}$ with $15 \mathrm{mg}$ immunobeads: a goat anti-rabbit immunoglobulin (Bio-Rad, Hercules, $\mathrm{CA})$ in $375 \mu \mathrm{l}$ radioimmunoassay buffer $(0.01 \mathrm{~mol}$ sodium phosphate $1^{-1}$ buffer; $\mathrm{pH} 7.4$, containing $0.14 \mathrm{~mol} \mathrm{NaCl} \mathrm{l}^{-1}, 0.5 \%$ $(\mathrm{w} / \mathrm{v}) \mathrm{BSA}$ and $0.01 \mathrm{~mol} \mathrm{EDTA}^{-1}$ ) and centrifuged at $2000 \mathrm{~g}$ for $30 \mathrm{~min}$. The supernatant was collected and lyophilized. The lyophilized powder was solubilized with $150 \mu \mathrm{l}$ deionized distilled water and $50 \mu \mathrm{l}$ aliquots, in duplicate, were taken for a double-antibody radioimmunoassay (Farmer and Papkoff, 1979). Highly purified eCG (about $15000 \mathrm{iu} \mathrm{mg} \mathrm{l}^{-1}$; kindly provided by H. Papkoff; University of California, San Francisco) was radioiodinated by the iodogen method of Frakes and Speck (1978). The iodogen was purchased from Pierce Chemical Co. (Rockford, IL). The specific activity of the iodinated hormone was $40 \mu \mathrm{Ci} \mu g^{-1} \mathrm{l}^{-1}$; it was stored in aliquots at $-20^{\circ} \mathrm{C}$ and used within a month. Before the assay, labelled eCG was purified on a $6 \mathrm{~cm}$ Sephadex G-75 column.

Standards were prepared by serial dilutions of Papkoff's eCG preparation in radioimmunoassay buffer. Samples and serial dilutions of standards $(50 \mu \mathrm{l})$ were added with $50 \mu \mathrm{l}$ of rabbit anti-eCG serum (final concentration 1:80 000) dissolved in 3\% (v/v) NRS and incubated for $24 \mathrm{~h}$ (Farmer and Papkoff, 1979). Iodinated eCG (at a concentration of 10 000-15 000 c.p.m. per $50 \mu \mathrm{l})$ was then added to each tube and they were incubated at $4^{\circ} \mathrm{C}$ for $24 \mathrm{~h}$. To the tubes for nonspecific binding (50 $\mu \mathrm{l}$ NRS, without eCG-antiserum) and total binding, $50 \mu \mathrm{l}$ of diluted (1:16) second antibody was then added and the tubes were incubated at $4^{\circ} \mathrm{C}$ for $18 \mathrm{~h}$. The second antibody was goat anti-rabbit serum (Antibodies Inc., Davis, CA). At the end of incubation, $1 \mathrm{ml}$ PBS was added and the tubes were centrifuged at $2000 \mathrm{~g}$ for $30 \mathrm{~min}$. The supernatant was discarded and the pellets counted in a gamma spectrometer.

\section{Radioimmunoassays of steroids}

Concentrations of oestradiol, progesterone and androstenedione were determined by validated methods (Terranova and Greenwald, 1978; Roy and Greenwald, 1987) for both serum and incubation medium samples.

\section{Statistical analyses}

Student's $t$ test was used where appropriate (Fig. 1). Data in Figs 2-5 were analysed by analysis of variance carried out with the SUPER ANOVA program of Abacus Concepts, Inc. (Berkeley, CA) followed by Duncan's new multiple-range test. Differences at a probability of $P<0.05$ were considered statistically significant.

\section{Results}

\section{Follicular steroidogenesis in vitro}

In antral follicles dissected from hypophysectomized eCGtreated hamsters and incubated in vitro, after $1 \mathrm{~h}$, accumulation 


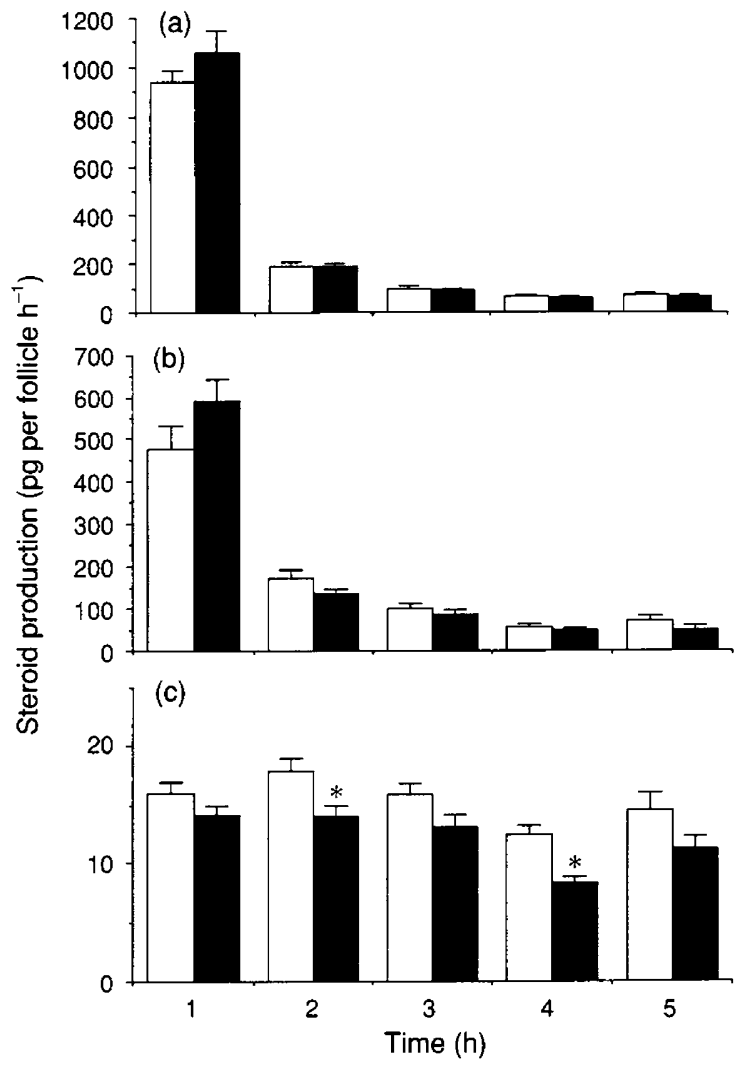

Fig. 1. Accumulation of follicular steroids in vitro: (a) oestradiol, (b) androstenedione and (c) progesterone. Follicles were removed at $\mathrm{Oh}$ (before eCG antiserum) and the medium was changed every hour for a total of $5 \mathrm{~h}$. For the control follicles ( $\square$ ), I0 $\mu \mathrm{l}$ of normal rabbit serum was added and to the other group $(\boldsymbol{\square}), 10 \mu \mathrm{l}$ of eCG antiserum was added from $2 \mathrm{~h}$ onwards. Values for progesterone production were significantly different $(P<0.05)$ from controls $\left({ }^{*}\right)$ at $2 \mathrm{~h}$ and $4 \mathrm{~h}$ by Student's $t$ test ( $n=12$ replicates for oestradiol; $n=8$ for androstenedione and progesterone).

of oestradiol and androstenedione in the medium was high, there was a marked decline in the second hour and a further decrease in the third hour; the nadir was reached by the fourth and fifth hours (Fig. 1). However, the production of progesterone was only a fraction of oestradiol accumulation and did not change over the entire incubation. In the control group, $10 \mu \mathrm{l}$ NRS was added every hour. Adding $10 \mu \mathrm{l}$ eCG antiserum every hour failed to alter the steroidogenic profile obtained in vitro; i.e., there was no acceleration of the rate of decline of oestradiol and androstenedione compared with that of control follicles. After the fifth hour of incubation, the follicles were used for histology; $75 \%$ were healthy and $25 \%$ showed signs of early atresia. There was no difference in the percentage of atretic follicles between control follicles and follicles treated with eCG antiserum.

It was initially surprising that the effects of eCG on follicular steroidogenesis in vitro lasted for only $1 \mathrm{~h}$, although serum concentrations of eCG were still high on the morning of day 4 (Bill and Greenwald, 1981). Consequently, in the next experiment, 1.0 iu eCG was added to the follicles at the second hour of incubation. The control follicles again showed a sharp decline in oestradiol, whereas adding eCG maintained high

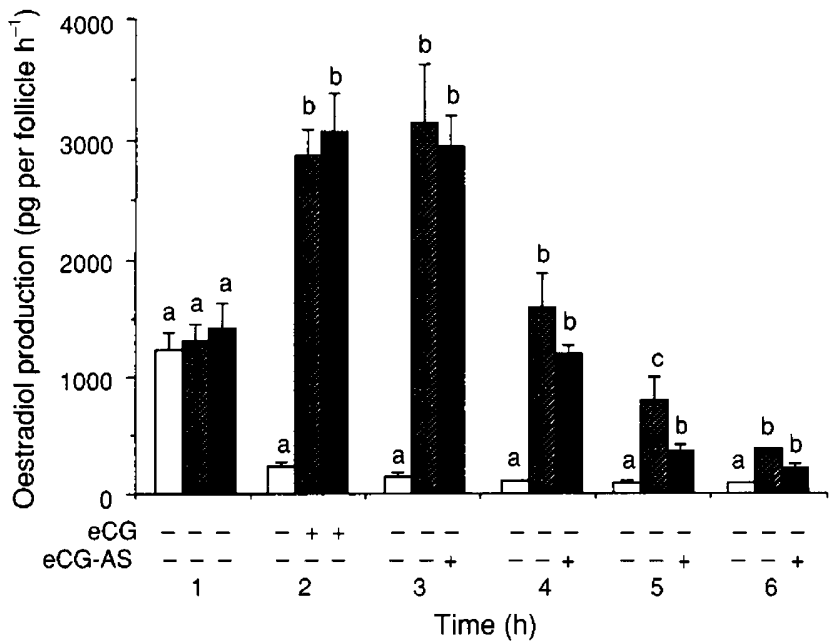

Fig. 2. Effect of addition of 1.0 iu eCG in vitro only in the second hour on oestradiol accumulation over the subsequent $4 \mathrm{~h}$ (眬). Another group received 1.0 iu eCG in the second hour and thereafter $10 \mu \mathrm{l}$ eCG-antiserum (eCG-AS) in h3-h6 ( $\mathbf{\square}$ ). Untreated, control follicles $(\square)$. By Duncan's new multiple-range test, eCG groups are significantly different $(P<0.01)$ from control groups at h2-h6. There were four replicates for each group. Bars labelled with different letters are significantly different $(P<0.05)$.

concentrations of oestradiol for $2 \mathrm{~h}$ with a gradual fall (Fig. 2). When eCG antiserum was added from the third hour onwards, oestradiol accumulation at the fifth hour was significantly different from the value of follicles exposed only to eCG; at all other times, however, oestradiol production did not differ between the two groups. The medium was changed every hour so that the added eCG was washed out at the end of the second hour. Hence, the robust stimulation of oestradiol synthesis for $2 \mathrm{~h}$ by eCG in vitro represents a sustained direct follicular effect.

In the next experiment, in one group $1.0 \mathrm{iu}$ eCG was added every hour from $2 \mathrm{~h}$; another group received eCG plus $10 \mu \mathrm{l} \mathrm{eCG}$ antiserum on the same schedule (Fig. 3). Addition of eCG every hour maintained oestradiol at about $1500 \mathrm{pg}$ per follicle throughout the $4 \mathrm{~h}$ incubation, whereas addition of eCG antiserum consistently counteracted the effects of eCG in sustaining oestradiol synthesis. Addition of various amounts of eCG antiserum similarly negated the stimulatory effects of eCG in a dose-response manner; oestradiol accumulation in the medium was reduced to $288 \pm 20,148 \pm 22$ and $51 \pm 3 \mathrm{pg}$ per follicle after $5 \mathrm{~h}$ on adding 3,10,100 $\mu \mathrm{l}$ eCG antiserum, respectively. The control follicles, not exposed to eCG antiserum, again showed a steady fall in oestradiol after the first hour.

\section{Serum oestradiol and androstenedione and unbound eCG before and after injecting eCG antiserum}

Before injecting eCG antiserum, serum oestradiol was approximately 2.5 times higher than androstenedione (Fig. 4). However, within $1 \mathrm{~h}$ after the i.p. injection of eCG antiserum, androstenedione was no longer detectable and oestradiol concentrations also showed a further marked reduction by $2 \mathrm{~h}$. 


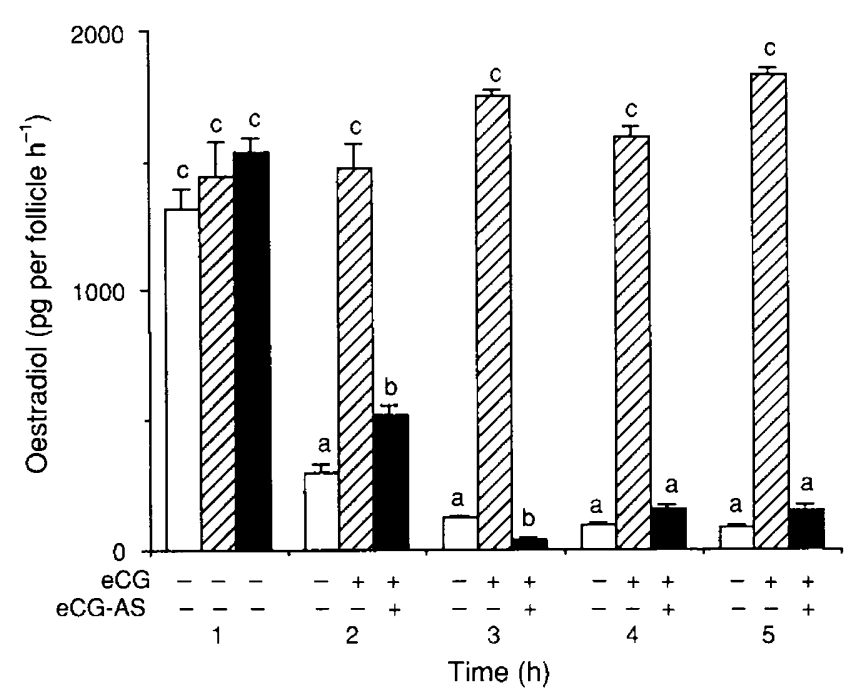

Fig. 3. Effect of addition of 1.0 iu eCG in vitro from $2 \mathrm{~h}$ and every hour thereafter $(\square)$. Another group received $10 \mu \mathrm{l}$ eCG antiserum plus eCG (eCG-AS) from $2 \mathrm{~h}$ onwards $(\square)$. The control group ( $\square$ ) had $10 \mu$ normal rabbit serum added in hI-h5. Duncan's new multiplerange test was used to compare the three groups. Bars labelled with different letters are significantly different $(P<0.05)$. Averages are based on four replicates.

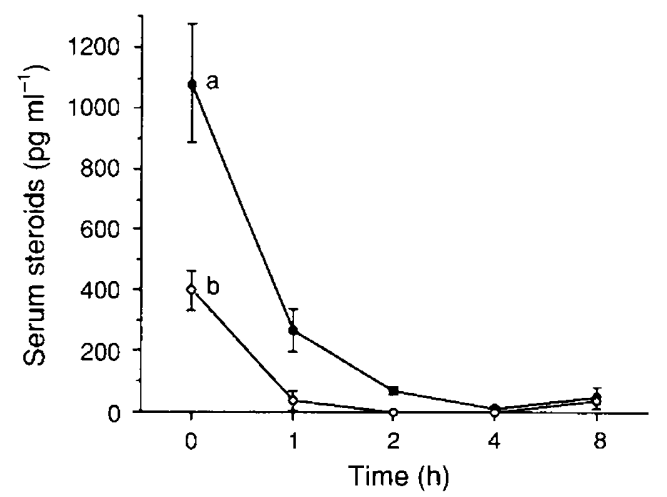

Fig. 4. Serum (a) oestradiol and (b) androstenedione (mean \pm SEM; $n=4)$ at $O \mathrm{~h}$ and $1-8 \mathrm{~h}$ after eCG antiserum. Serum androstenedione was not detectable after $0 \mathrm{~h}$. Values at $1-8 \mathrm{~h}$ are significantly different $(P<0.01)$ from values at $\mathrm{oh}$ by Duncan's new multiple-range test.

Before injecting eCG antiserum, concentration of free eCG was high in serum, and correlated with the high circulating concentrations of the steroids (Fig. 5). However, within $1 \mathrm{~h}$ after eCG antiserum, a sharp decline in unbound eCG was observed with no further change over the next $7 \mathrm{~h}$. Thus, after the administration of eCG antiserum, the abrupt fall in steroid concentrations was paralleled by an equally abrupt fall in free, unbound eCG (Figs 4 and 5).

\section{Discussion}

These studies on steroidogenesis in vitro revealed that, before injecting eCG antiserum, follicles secreted large amounts of

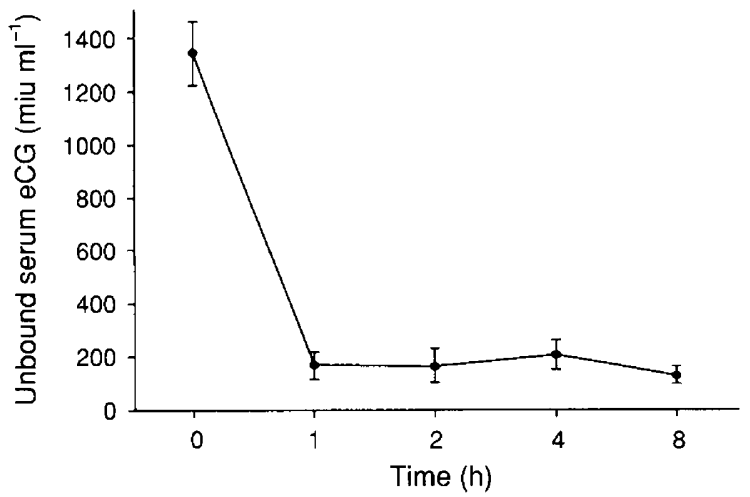

Fig. 5. Free (unbound) serum eCG before injection of eCG antiserum and after the i.p. injection of eCG. The same serum samples used in Fig. 4 were used to determine eCG. Values at $\mathrm{I}-8 \mathrm{~h}$ were significantly different $(P<0.05)$ from $0 \mathrm{~h}$ by Duncan's multiple-range test.

oestradiol and androstenedione only in the first hour of incubation. Moreover, addition of eCG antiserum in vitro did not accelerate the fall in steroid production. This finding suggests that the constant availability of eCG in vivo is essential for optimal secretion of oestradiol and androstenedione, although the long-term effect of eCG in vitro - albeit at a lower concentration - was still observed. For example, in the fifth hour of incubation, about $100 \mathrm{pg}$ oestradiol per follicle was still accumulating in the medium. Follicles from normal intact cyclic hamsters on the morning of pro-oestrus secrete about $250 \mathrm{pg}$ of oestradiol after a $1 \mathrm{~h}$ incubation (Wang and Greenwald, 1984).

The fall in oestradiol and androstenedione after the first hour of incubation of the eCG follicles was temporarily reversed by a single addition of eCG at the second hour and was maintained by addition of the hormone every hour. The addition of eCG-antiserum every hour was very effective in curtailing oestradiol secretion, by inactivating the eCG added to the medium. Collectively, these experiments demonstrate that constant exposure to high concentrations of eCG in vitro is essential to sustain supraphysiological production of steroids, and this suggests that the major effect of eCG antiserum in vivo is not at the ovary but in the serum, where it complexes with eCG, rapidly inactivating the circulating hormone. However, the possibility that eCG antiserum acts by binding to unoccupied ovarian receptors, thus preventing additional eCG from binding and activating thecal and granulosa cells, cannot be excluded.

The hypothesis that eCG antiserum inactivates eCG in serum was confirmed in the final experiment, in which eCG bound to eCG antiserum was eliminated by incubating serum with a goat anti-rabbit immunoglobulin so that free eCG (i.e., unbound) could be measured. An eightfold fall in free eCG by $1 \mathrm{~h}$ after eCG antiserum coincided with the fall in serum oestradiol and androstenedione. Some unbound eCG was still present in the serum over the next $7 \mathrm{~h}$ but was insufficient to maintain increased serum oestradiol or androstenedione.

The authors thank $\mathrm{H}$. Papkoff for providing the purified eCG and the National Hormone and Pituitary Program, NIDDK, for furnishing 
the gonadotrophins. This work was supported by NIH grants HD00596(31) and HD0252.

\section{References}

Aggarwal BB and Papkoff H (1981) Studies on the disappearance of equine chorionic gonadotropin from the circulation in the rat: tissue uptake and degradation Endocrinology 109 1242-1247

Alberts B, Gray D, Lewis J, Roff M, Roberts K and Watson JD (Eds) (1989) Molecular Biology of the Cell (2nd edn) pp 333-334. Garland Publishing, New York

Bill CH and Greenwald GS (1981) Acute gonadotropin depletion. I. A model for the study of atresia Biology of Reproduction 24 913-921

Cole HH (1975) Studies on reproduction with emphasis on gonadotropins, anti-gonadotropins and progonadotropins Biology of Reproduction 13 194-211

Cole HH and Hart G (1930) The potency of blood serum of mares in progressive stages of pregnancy in effecting the sexual maturity of the immature rat American Journal of Physiology 93 57-68

Farmer SW and Papkoff H (1979) Immunochemical studies with pregnant mare serum gonadotropin Biology of Reproduction 21 425-431
Frakes JF and Speck JC, Jr (1978) Protein and cell membrane iodinations with a sparingly soluble chloroamide, 1,3,4,6-tetrachloro-3a-6a diphenylglycoluril Biochemistry and Biophysics Research Communications 80 849-857

Greenwald GS (1989) Temporal and topographic changes in DNA synthesis after induced follicular atresia Biology of Reproduction 41 175-181

Murphy BD and Martinuk SD (1991) Equine chorionic gonadotropin Endocrine Reviews 12 27-44

Papkoff H, Bewley TA and Ramachandran J (1978) Physiochemical and biological characterizations of pregnant mare serum gonadotropin and its subunits Biochimica et Biophysica Acta 532 185-194

Parlow AF and Ward DN (1961) Rate of disappearance of LH, PMS and HCG from plasma. In Human Pituitary Gonadotropins. Gonadotropic Activity of Human Blood pp 204-209 Ed. A Albert. Charles C Thomas, Springfield

Roy SK and Greenwald GS (1987) In vitro steroidogenesis by primary to antral follicles in the hamster during the periovulatory period: effects of follicle stimulating hormone, luteinizing hormone and prolactin Biology of Reproduction 37 39-46

Terranova PF and Greenwald GS (1978) Steroid and gonadotropin levels during the luteal-follicular shift of the cyclic hamster Biology of Reproduction 18 170-175

Wang SC and Greenwald GS (1984) Effect of lipoproteins, 25hydroxycholesterol and luteinizing hormone on in vitro follicular steroidogenesis in the hamster and rat Biology of Reproduction 31 271-278

Zondek BD (1930) Hormonale schwangerschaftst-reaktion aus dem harn bei mensch und tier Klinische Wochenschrift 9 2285-2289 